Praxis : Jurnal Sains, Teknologi, Masyarakat dan Jejaring | Vol. 4 | No. 1 | September 2021

\title{
Efisiensi Pada Sepeda Listrik Dengan Dinamo Sepeda Sebagai Generator
}

\author{
Fathan Mubina Dewadi \\ Universitas Katolik Soegijapranata, Semarang \\ email: fdewadi@gmail.com
}

\begin{abstract}
Abstrak
Penelitian ini mengacu kepada kelebihan dinamo sepeda terhadap sepeda listrik yaitu kemampuannya yang bisa menghemat bahan bakar. Sebab jenis kendaraan ini hanya menggunakan arus listrik sebagai bahan bakarnya. Harganya yang murah dan juga modelnya yang mirip dengan model sepeda motor biasa memastikan bahwa tidak akan ada bedanya antara sepeda listrik dengan sepeda motor bahan bakar fosil. Di era yang serba keterbaruan ini, kendaraan listrik dapat dijadikan sebagai kendaraan masa depan yang lebih baik dengan baterai sebagai sumber energi. Metode yang dilakukan dengan cara manual dan mengambil intisari dari beberapa referensi terkait kemudian ambil persamaanpersamaan mendukung sehingga menjadi sebuah inovasi penelitian dalam memunculkan sebuah inovasi penelitian. Tak luput juga melakukan studi banding penelitian ini dengan penelitian sebelumnya. Optimasi penelitian dengan menambahkan dinamo sepeda sebagai generator dapat menghemat daya hingga $0.05 \mathrm{Wh}$ pada jarak $300 \mathrm{~m}$. Terbukti dalam penelitian di jarak $300 \mathrm{~m}, E$-Bike yang menggunakan dinamo sepeda hanya menghabiskan harga $\mathrm{Rp} 4,14 / 300 \mathrm{~m}$, E-Bike yang menggunakan trafo menghabiskan harga Rp 4,2/300 m. Daya listrik pada jarak $300 \mathrm{~m}$ dengan dinamo sepeda menghabiskan daya $271.59 \mathrm{~W}$ sedangkan daya listrik pada jarak $300 \mathrm{~m}$ dengan trafo step-down menghabiskan daya $295.02 \mathrm{~W}$, dan terbukti dinamo sepeda lebih efisien dalam konsumsi energi listrik.
\end{abstract}

Kata Kunci : Bahan bakar, Sepeda Listrik, Dinamo Sepeda.

\begin{abstract}
This research refers to the advantages of a bicycle dynamo over an electric bicycle, namely its ability to save fuel. Because this type of vehicle only uses electric current as fuel. Their low prices and similar models of motorbikes ensure that there is no difference between an electric bicycle and a fossil fuel motorbike. Electric vehicles have developed, ranging from twowheeled, four-wheeled, trains, to carts paired with electric motors that use batteries. The method is done manually and takes the essence of several related references then takes the supporting equations so that it becomes a research innovation in generating a research innovation. Do not forget to also conduct a comparative study of this research with previous research. Research optimization by adding a bicycle dynamo as a generator can save power up to 0.05 What a distance of $300 \mathrm{~m}$. It is proven in research at a distance of $300 \mathrm{~m}$, an EBike that uses a bicycle dynamo costs only Rp.4.14 / 300m, an E-Bike that uses a transformer costs Rp.4.2 / 300m. Electric power at a distance of $300 \mathrm{~m}$ with a bicycle dynamo consumes $271.59 \mathrm{~W}$ while electric power at a distance of $300 \mathrm{~m}$ with a step-down transformer consumes $295.02 \mathrm{~W}$, and it is proven that bicycle dynamos are more efficient in consuming electrical energy.
\end{abstract}

Keywords: fuel, electric bicycle, bicycle dynamo. 
Praxis : Jurnal Sains, Teknologi, Masyarakat dan Jejaring | Vol. 4 | No. 1 | September 2021

\section{PENDAHULUAN}

Sepeda listrik atau yang biasa disebut electric-bike (E-Bike) adalah sepeda dengan sumber tenaga listrik yang berasal dari baterai (Prayoga, 2017). Seiring dengan perkembangan zaman, pendidikan dan teknologi maka kehadiran sepeda listrik di kancah dunia transportasi semakin menonjol dengan munculnya inovasi seperti sepeda listrik dengan trafo. Sepeda listrik dengan trafo diperuntukkan sesuai dengan kebutuhan si pengendara agar pengendara dapat memposisikan sepeda listrik tersebut sesuai fungsinya (Huda \& Khamami, 2017). Sebagai contoh jika pengendara ingin menaikkan arus agar sepeda lebih bertenaga maka digunakan trafo step-up sebagai tambahan komponen untuk memacu arus. Sebaliknya ada juga pengendara yang tidak memerlukan sepeda listrik dengan kecepatan tinggi namun untuk kecepatan tidak terlalu tinggi agar lebih efisien daya dan lebih ramah lingkungan serta aman dalam penggunaan. Dalam hal tersebut dibutuhkan sepeda listrik dengan trafo step-down. Namun karena sepeda listrik belum bisa diterima masyarakat dengan baik, maka terdapat juga inovasi pada kendaraan roda dua salah satunya dengan eco-racing. Dimana ecoracing merupakan sebuah suplemen dari tumbuhan yang berfungsi untuk meningkatkan efisiensi pemakaian bahan bakar pada sepeda motor (Amir, Yuseva, \& Sumanto, 2020). Sepeda motor dengan eco-racing merupakan sepeda motor dengan bantuan eco-racing sebagai suplemen untuk meningkatkan efisiensi konsumsi bahan bakar (W.H, 2020). Namun pada penelitian ini hanya akan dibahas mengenai nilai sepeda listrik dengan trafo step-down dan sepeda listrik dengan dinamo sepeda (Wildan, 2019).

Kelebihan yang menonjol dari sepeda listrik adalah kemampuannya yang bisa menghemat bahan bakar. Sebab jenis kendaraan ini hanya menggunakan arus listrik sebagai bahan bakarnya. Harganya yang murah dan juga modelnya yang mirip dengan model sepeda motor biasa memastikan bahwa tidak akan ada bedanya antara sepeda listrik dengan sepeda motor bahan bakar fosil (Hutabalian and Hamzah 2016). Dengan inovasi yang mampu bersaing secara global, kendaraan listrik tetap harus terdepan sebagai kendaraan yang efisien dimasa depan seiring makin langka krisis BBM (Ayuni Priansa 2019). Kendaraan konvensional lama kelamaan tidak akan bertahan lama dan terusmenerus dipakai karena seiring dengan kelangkaan bahan bakar energi fosil. Yang dimaksud kendaraan konvensional ialah kendaraan yang masih menggunakan energi tak terbarukan yaitu energi fosil dalam sumber energinya (Harfit, 2013).

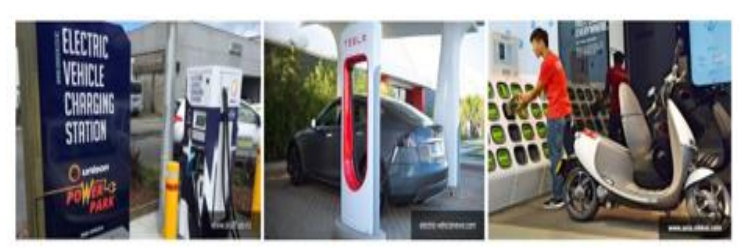

Gambar 1. Model pengisisan ulang teknologi mutakhir

Pengisian energi listrik pada kendaraan listrik yang efektif sangat diperuntukkan demi kehidupan yang lebih memadai. Pemilik kendaraan listrik dapat menerapkan wadah pengisian di tempat yang tejangkau untuk dilakukan pengisian energi listrik. Sebuah metode yang cukup efisien meski pengisian energi listrik tidak secepat yang beberapa masyarakat pikirkan. Pada negara maju sudah dikembangkan stasiun pengisian energi listrik. Namun, pengisian energi listrik tidak secepat pengisian pada SPBU di stasiun BBM karena media yang cukup sensitif serta pada peralatan listrik butuh penyesuaian lebih dalam pemindah energi listrik (Subuh Isnur Haryudo 2019). Pengisian menggunakan energi listrik merupakan salah satu metode yang inovatif dalam mempermudah kebutuhan teknologi. Fasilitas pendukung sangat dibutuhkan dalam mempermudah mobilisasi pengguna 
Praxis : Jurnal Sains, Teknologi, Masyarakat dan Jejaring | Vol. 4 | No. 1 | September 2021

kendaraan listrik (Dahlan, Zariatin, and Wibowo 2018). Tempat pengisian umum energi listrik dapat diterapkan di tempattempat umum yang terjangkau oleh berhentinya kendaraan. Stasiun pengisian umum dinilai mendukung jangkauan yang lebih jauh dan proses pengisian lebih cepat (Prasetyo, Dahlan, and Fadhli 2018). Dalam pengisian energi seiring infrastruktu baterai belum memadai, maka dari itu diperlukan sebuah teknik pengisian yang relevan yaitu sistem pengisian tukar baterai (Abagnale et al. 2016). Metode tukar baterai dengan baterai penuh dan kosong atau biasa disebut dengan istilah swapping battery cukup efisien dalam pengisian energi karena konsumen tidak perlu lamalama menunggu pengisian energi dan bisa terbilang cukup isntan (Sepdian and Subama 2019). Perlunya sebuah standarisasi yang mumpuni agar pengisian ulang energi listrik menjadi relevan dalam pemakaian energi listrik (Surapati and Priyadi 2018).

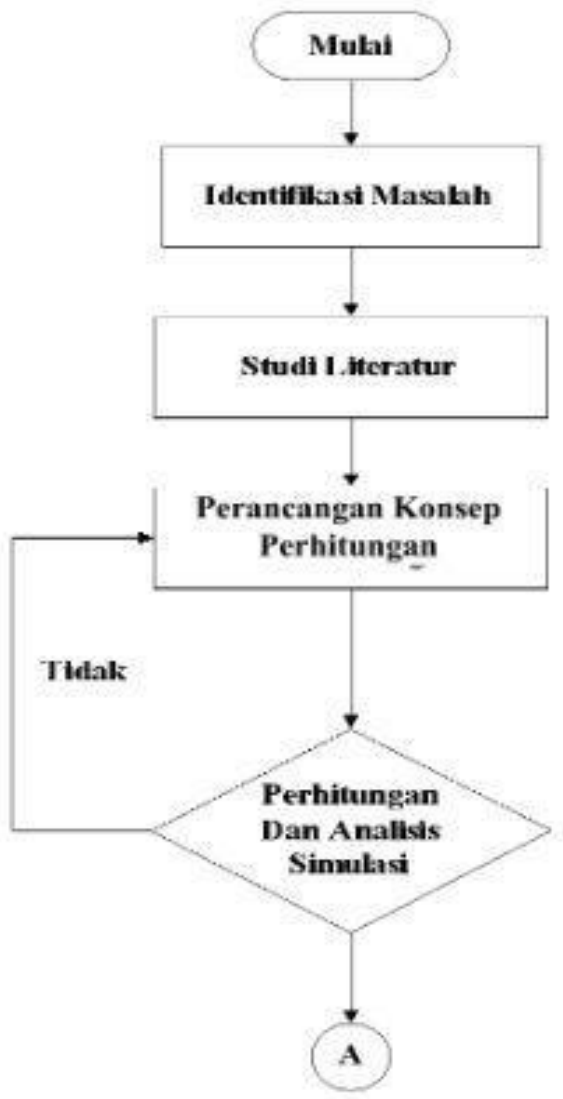

\section{METODE PENELITIAN}

Dalam menganalisis data penelitian yang akan dijadikan sebuah optimasi, langkah awal yaitu menghitung konsumsi energi baterai karena tahap ini merupakan awal simulasi penelitian, lalu menghitung durasi baterai dapat memback-up beban. Kemudian menghitung waktu pengisian baterai yang terjadi. Selanjutnya menghitung konsumsi E-Bike dari sisi ekonomis. Setelah sisi ekonomis sudah dihitung barulah mengitung waktu pengisian energi listrik yang menggunakan dinamo sepeda. Hasil perhitungan akhir sebagai perbandingan $E$-Bike biasa dan $E$ Bike yang menggunakan dinamo sepeda, maka dari itu optimasi dinamo sepeda pada E-Bike harus lebih optimal.

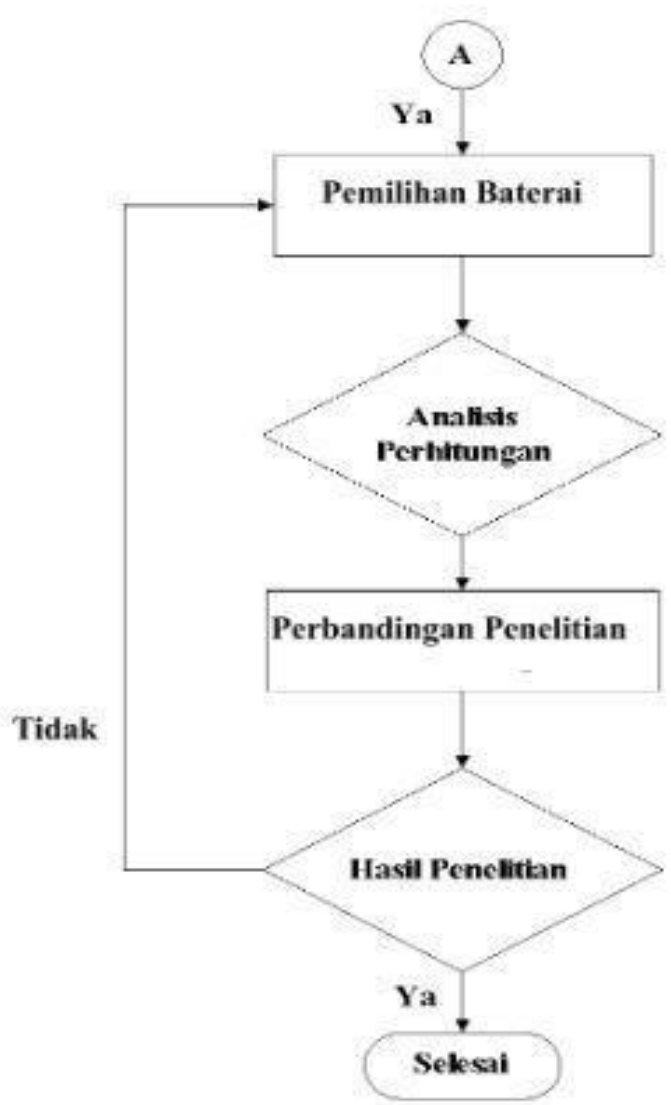

Gambar 2. Tahapan Pengambilan Data 
Praxis : Jurnal Sains, Teknologi, Masyarakat dan Jejaring | Vol. 4 | No. 1 | September 2021

Metode yang dilakukan dengan cara manual dan mengambil intisari dari beberapa referensi terkait kemudian ambil persamaan-persamaan mendukung sehingga menjadi sebuah inovasi penelitian dalam memunculkan sebuah inovasi penelitian. Tak luput juga melakukan studi banding penelitian ini dengan penelitian sebelumnya.

\section{HASIL DAN PEMBAHASAN}

Berdasarkan yang telah dijelaskan pada latar belakang masalah, maka dari itu diuraikan batasan-batasan masalah yang harus diteliti lebih lanjut, yakni sebagai berikut :

- Apa konsep kebaruan sistem pada penelitian sepeda motor listrik ini?

- Seberapa besar pengaruh dinamo sepeda pada efisiensi sepeda motor listrik?

- Bagaimana dinamo sepeda menjadi optimasi komponen yang lebih baik untuk sepeda motor listrik?

Instrumen yang difokuskan pada penelitian ini yaitu dinamo sepeda yang dapat berperan sebagai generator demi meningkatkan efisiensi konsumsi energi listrik pada E-Bike. Dengan mengandalkan putaran pada dinamo sepeda maka terciptalah gerak elektromagnetik yang didalamnya terdapat rotor dan stator sehingga timbul gaya gerak listrik (Ismail, 2020). Besar atau kecilnya energi yang dihasilkan dari dinamo sepeda tergantung dari putaran pada dinamo sepeda, semakin besar putaran dari sebuah roda maka berbanding lurus dengan putaran pada dinamo sepeda (Ridwanto and Broto 2017). Dinamo sepeda ibarat sebuah generator yang dikonversikan besar putarannya melalui putaran ban pada sepeda. Faktor besar gaya listrik pada dinamo sepeda yaitu jumlah kumparan, besar tegangan dan besar arus (Puspita, Sunarno, and Indarto 2017). Gambar dinamo terlampir pada gambar 3.

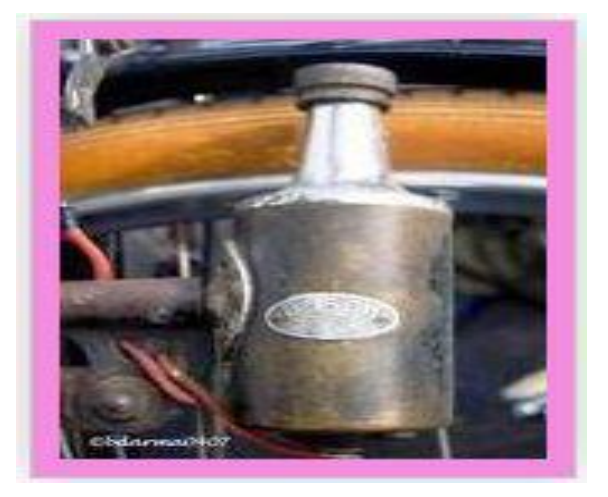

Gambar 3. Dinamo

Konsumsi energi yang dimaksud yaitu pemakaian energi pada sebuah sepeda listrik. Adanya penelitian ini diperuntukkan untuk meningkatkan efisiensi konsumsi energi. Efisiensi konsumsi energi merupakan kadar seberapa efisien pemakaian energi pada sepeda listrik ini. Untuk mengembangkan penelitian yang sudah ada dengan sebuah kebaruan maka diperlukan optimasi. Optimasi merupakan sebuah langkah agar mendapatkan hasil yang optimal dalam penelitian. Analisis hasil pengukuran ini mengacu pada teknologi dinamo sepeda yang dapat mengisi ulang energi listrik dengan memanfaatkan putaran dari roda sehingga terjadi perubahan energi dari energi kinetik menjadi energi listrik. Dengan adanya data sebelumnya penelitian pun jadi mudah dikembangkan dengan gagasan-gagasan yang sudah ada sehingga perlu pembaruan kembali. Sistem menggunakan dinamo sepeda harus lebih baik dari penelitian sebelumnya dan diperlukan beberapa parameter perhitungan yaitu perhitungan konsumsi energi baterai, perhitungan durasi baterai dapat membackup beban, perhitungan waktu pengisian baterai, perhitungan konsumsi E-Bike dari sisi ekonomis, waktu pengisian baterai menggunakan dinamo sepeda. Data perhitungan konsumsi energi E-Bike dari penelitian sebelumnya akan dijelaskan 
Praxis : Jurnal Sains, Teknologi, Masyarakat dan Jejaring | Vol. 4 | No. 1 | September 2021

pada penelitian sebelumnya akan

dijelaskan pada tabel 1 (Siregar \& Dahlan,

2020).

Tabel 1. Data perhitungan konsumsi energi E-Bike

\begin{tabular}{|c|c|c|c|c|c|c|c|}
\hline \multirow{4}{*}{ No } & \multirow{4}{*}{$\begin{array}{l}\text { Parameter } \\
\text { Perhitungan }\end{array}$} & \multicolumn{6}{|c|}{ Kondisi Mendatar } \\
\hline & & \multicolumn{3}{|c|}{$\begin{array}{l}\text { E-Bike tanpa trafo step- } \\
\text { down }\end{array}$} & \multicolumn{3}{|c|}{$\begin{array}{c}\text { E-Bike dengan trafo step- } \\
\text { down }\end{array}$} \\
\hline & & \multicolumn{6}{|c|}{ Jarak } \\
\hline & & $100 \mathrm{~m}$ & $200 \mathrm{~m}$ & $300 \mathrm{~m}$ & $100 \mathrm{~m}$ & $200 \mathrm{~m}$ & $300 \mathrm{~m}$ \\
\hline 1 & $\mathrm{P}_{\text {total }}(\mathrm{W})$ & 298,15 & 364,57 & 368,78 & 238,52 & 291,66 & 295,02 \\
\hline 2 & $\mathrm{~W}(\mathrm{Wh})$ & 1,57 & 2,83 & 3,89 & 1,26 & 2,27 & 3,11 \\
\hline 3 & TDL (Rp) & 2,12 & 3,83 & 5,26 & 1,7 & 3,07 & 4,2 \\
\hline
\end{tabular}

Dari penelitian sebelumnya telah dijabarkan bahwa sepeda motor listrik biasa dan dengan teknologi trafo stepdown akan berpengaruh terhadap efisiensi konsumsi energi, ekspektasi penelitian ini

yaitu dengan ditambah teknologi dinamo sepeda. Perbandingan konsumsi energi kendaraan konvensional dan sepeda motor listrik dari data sebelumnya akan dijelaskan pada tabel 2 .

Tabel 2. Perbandingan konsumsi energi kendaraan konvensional dan sepeda motor listrik

\begin{tabular}{|c|c|c|c|c|}
\hline \multirow{2}{*}{ No } & \multirow{2}{*}{$\begin{array}{l}\text { Parameter } \\
\text { Kendaraan }\end{array}$} & \multicolumn{3}{|c|}{ Kondisi Mendatar } \\
\hline & & Jarak $100 \mathrm{~m}$ & Jarak $200 \mathrm{~m}$ & Jarak $300 \mathrm{~m}$ \\
\hline \multirow{3}{*}{1} & E-Bike: & & & \\
\hline & $\begin{array}{l}\text { Tanpa trafo } \\
\text { step-down }\end{array}$ & Rp 2,12 & Rp 3,83 & Rp 5,26 \\
\hline & $\begin{array}{c}\text { Dengan trafo } \\
\text { step-down }\end{array}$ & Rp 1,7 & Rp 3,07 & $\operatorname{Rp} 4,2$ \\
\hline \multirow{5}{*}{2} & $\begin{array}{c}\text { Sepeda motor } \\
\text { tanpa Eco } \\
\text { racing: }\end{array}$ & & & \\
\hline & Premium & Rp 6,38 & Rp 12,76 & $\operatorname{Rp} 19,14$ \\
\hline & Pertalite & Rp 5,89 & Rp 11,78 & Rp 17,67 \\
\hline & Pertamax & Rp 7,05 & Rp 14,1 & $\mathrm{Rp} 21,15$ \\
\hline & $\begin{array}{c}\text { Pertamax } \\
\text { Turbo }\end{array}$ & $\operatorname{Rp} 6,6$ & $\operatorname{Rp} 13,2$ & Rp 19,8 \\
\hline \multirow{5}{*}{3} & $\begin{array}{c}\text { Sepeda motor } \\
\text { dengan Eco } \\
\text { racing: }\end{array}$ & & & \\
\hline & Premium & Rp 3,64 & Rp 7,28 & Rp 10,92 \\
\hline & Pertalite & Rp 3,33 & Rp 6,66 & Rp 9,99 \\
\hline & Pertamax & Rp 3,82 & Rp 7,64 & $\mathrm{Rp} 11,46$ \\
\hline & $\begin{array}{c}\text { Pertamax } \\
\text { Turbo }\end{array}$ & Rp 3,59 & Rp 7,18 & Rp 10,77 \\
\hline
\end{tabular}


Praxis : Jurnal Sains, Teknologi, Masyarakat dan Jejaring | Vol. 4 | No. 1 | September 2021

Dalam merencanakan perhitungan penelitian electric motor bike dengan dinamo sepeda sebagai alat bantu penghasil listrik (generator). Pada tahap ini nantinya akan dibandingkan nilai untuk membandingkan efisiensi terkait daya listrik, energi dan tarif daya listrik.

1. Durasi penggunaan baterai dapat memback-up beban

Ringkasan data mengenai nilai tegangan dan kuat arus berdasarkan jarak dan kecepatan akan dipaparkan pada tabel 3.

Tabel 3. Nilai tegangan dan kuat arus berdasarkan jarak dan kecepatan

\begin{tabular}{|c|c|c|c|c|}
\hline No & Jarak $(\mathrm{m})$ & Kecepatan $(\mathrm{m} / \mathrm{s})$ & Tegangan $(\mathrm{V})$ & Kuat Arus $(\mathrm{A})$ \\
\hline 1 & 100 & 5.5 & 5.6 & 2.07 \\
\hline 2 & 200 & 7.14 & 7.6 & 2.69 \\
\hline 3 & 300 & 7.89 & 7.89 & 2.97 \\
\hline
\end{tabular}

Perhitungan penggunaan baterai untuk memback-up beban dengan perbedaan jarak yaitu $100 \mathrm{~m}, 200 \mathrm{~m}$ dan $300 \mathrm{~m}$ serta dibutuhkan nilai kuat arus dalam perhitungannya. Durasi baterai dalam perhitungan waktu memback-up beban dapat dihitung dengan persentase $80 \%$ dari perbandingan kapasitas baterai berbanding arus yang mengalir pada rangkaian sepeda motor listrik (Simatupang, Dewadi, Nugraha, \& Muhammad Rafdi, 2013). Nilai kapasitas baterai pada penelitian ini sebesar 30 Ah. Berdasarkan kecepatan kendaraan yang berbeda-beda akan dijabarkan perhitungan seperti dibawah (Wijaya 2015).

- $\mathrm{t}_{1}=80 \% . \mathrm{C} / \mathrm{I}=0.8 \times 30 / 2.07=11.59 \mathrm{~s}$ (100 m)

- $\mathrm{t}_{2}=80 \% . \mathrm{C} / \mathrm{I}=0.8 \times 30 / 2.69=8.92 \mathrm{~s}$ (200 m)

- $\mathrm{t}^{3}=80 \% . \mathrm{C} / \mathrm{I}=0.8 \times 30 / 2.97=8.08 \mathrm{~s}$ (300 m)

2. Perhitungan daya listrik yang masuk ke baterai

Nilai arus dan tegangan didapat berdasarkan analisis penelitian sebelumnya yang berkaitan langsung dengan penelitian ini yaitu dengan tegangan dibagi nilai kuat arus (Noor, 2017). Perhitungan daya listrik yang masuk ke baterai akan dijelaskan pada penjabaran berikut dengan mengkalikan nilai tegangan dan nilai arus.

- $\quad \mathrm{P}_{\text {in }}=5.6 \mathrm{~V} \times 2.07 \mathrm{~A}=11.59 \mathrm{~W}$

- $\mathrm{P}_{\text {in }}=7.6 \mathrm{~V} \times 2.69 \mathrm{~A}=20.44 \mathrm{~W}$

- $\quad \mathrm{P}_{\text {in }}=7.89 \mathrm{~V} \times 2.97 \mathrm{~A}=23.46 \mathrm{~W}$

3. Perhitungan selisih daya listrik yang terjadi

Pengisian energi ke baterai perlu dilakukan analisis karena baterai mendapatkan daya masuk yang berasal dari putaran dinamo sepeda (Siswoyo, et al., 2014). Perhitungan pengisian daya ke baterai memerlukan nilai daya keluar dan daya masuk baterai dan akan dijelaskan pada:

- $\Delta \mathrm{P}=$ Pout $-\mathrm{Pin}=238.52-11.59=$ $226.93 \mathrm{~W}$

- $\Delta \mathrm{P}=$ Pout $-\mathrm{Pin}=291.66-20.44=$ $271.22 \mathrm{~W}$

- $\Delta \mathrm{P}=$ Pout - Pin $=295.02-23.46=$ $271,56 \mathrm{~W}$

4. Perhitungan energi masuk baterai

Energi yang masuk ke baterai akan diubah dulu nilainya kedalam inverter yang selanjutnya nilai perhitungannya didapat 
Praxis : Jurnal Sains, Teknologi, Masyarakat dan Jejaring | Vol. 4 | No. 1 | September 2021

dengan mengkalikan daya masuk dikali waktu tiap jarak analisis (Alifyanti, 2016). Berikut akan dijabarkan penjabaran analisis perhitungan energi masuk baterai.

- $\mathrm{W} 1=$ Pin $\mathrm{x} \mathrm{t} 1=11.59 \times 11.59=0.04$ Wh (100 m)

- $\mathrm{W} 2=$ Pin $\times \mathrm{t} 2=20.44 \times 8.92=0.051$ $\mathrm{Wh}(200 \mathrm{~m})$

- $\mathrm{W} 3=\mathrm{Pin} \times \mathrm{t} 3=23.46 \times 8.08=0.053$ Wh (300 m)

5. Perhitungan konsumsi energi yang terjadi pada baterai

Untuk analisis perhitungan konsumsi energi yang terjadi pada baterai didapat dengan nilai energi yang keluar pada tabel 1 lalu dikurangi nilai energi yang masuk ke baterai (Saodah \& Hariyanto, 2019). Berikut penjabaran dari analisis perhitungan dibawah.

- $\Delta \mathrm{W}=$ Wout - Win $=1.26-0.04=$ $1.22 \mathrm{Wh}(100 \mathrm{~m})$

- $\Delta \mathrm{W}=$ Wout - Win $=2.27-0.051=$ $2.22 \mathrm{Wh}(100 \mathrm{~m})$

- $\Delta \mathrm{W}=$ Wout - Win $=3.11-0.053=$ $3.057 \mathrm{Wh}(100 \mathrm{~m})$
6. Perhitungan konsumsi E-Bike dari sisi ekonomis

Perhitungan ekonomis dari harga listrik untuk konsumsi baterai pada E-Bike dapat dihitung ketika mengkonsumsi listrik (Wijaya, 2015). Harga dasar listrik yang didapat adalah Rp 1,352.00 / kWh. Karena $1 \mathrm{~kW}$ merupakan $1000 \mathrm{~W}$ maka nilai $\Delta \mathrm{W}$ harus dibagi dengan 1000. Berikut akan dijabarkan analisis perhitungan konsumsi E-Bike dari sisi ekonomis pada persamaan dibawah ini.

- $\quad \mathrm{TDL}=1.22 / 1000 \times \mathrm{Rp} 1.352=\mathrm{Rp}$ $1.65(100 \mathrm{~m})$

- $\mathrm{TDL}=2.22 / 1000 \times \mathrm{Rp} 1.352=\mathrm{Rp}$ $2.97(100 \mathrm{~m})$

- $\mathrm{TDL}=3.06 / 1000 \times \mathrm{Rp} 1.352=\mathrm{Rp}$ $4.14(100 \mathrm{~m})$

Kebaruan sistem dengan menggunakan dinamo sepeda cukup inovatif dalam analisis perhitungan karena nilai output sepeda listrik dengan dinamo sepeda lebih efisien dibanding sepeda listrik dengan trafo step-down. Data studi banding penelitian ini yaitu dengan mengacu pada kondisi mendatar. Berikut akan dipaparkan pada tabel 4.

Tabel 4. Perbandingan kondisi mendatar

\begin{tabular}{|c|c|c|c|c|c|c|c|}
\hline \multirow{3}{*}{ No } & \multirow{3}{*}{$\begin{array}{l}\text { Parameter } \\
\text { Perhitungan }\end{array}$} & \multicolumn{6}{|c|}{ Kondisi Mendatar } \\
\hline & & \multicolumn{3}{|c|}{$\begin{array}{c}\text { E-Bike dengan trafo step } \\
\text { down }\end{array}$} & \multicolumn{3}{|c|}{$\begin{array}{c}\text { E-Bike dengan dinamo } \\
\text { sepeda }\end{array}$} \\
\hline & & $100 \mathrm{~m}$ & $200 \mathrm{~m}$ & $300 \mathrm{~m}$ & $100 \mathrm{~m}$ & $200 \mathrm{~m}$ & $300 \mathrm{~m}$ \\
\hline 1 & Ptotal (W) & 238,52 & 291,66 & 295,02 & 226,93 & 271,22 & 271,56 \\
\hline 2 & $\mathrm{~W}(\mathrm{Wh})$ & 1,26 & 2,27 & 3,11 & 1,22 & 2,22 & 3,06 \\
\hline 3 & TDL (Rp) & 1,7 & 3,07 & 4,2 & 1,65 & 2,97 & 4,14 \\
\hline
\end{tabular}

\section{DISKUSI}

Hasil akhir penelian ini yaitu membandingkan hasil perhitungan antara e-bike dengan trafo step-down dan e-bike dengan dinamo sepeda. Berikut akan dipaparkan mengenai diagram nilai daya total, energi yang masuk ke baterai dan tarif dasar listrik pada gambar $4 \mathrm{~s} / \mathrm{d}$ gambar 6. Berikut akan dijelaskan pada gambar 4 mengenai perbandingan daya total pada kedua jenis sepeda listrik. 
Praxis : Jurnal Sains, Teknologi, Masyarakat dan Jejaring | Vol. 4 | No. 1 | September 2021

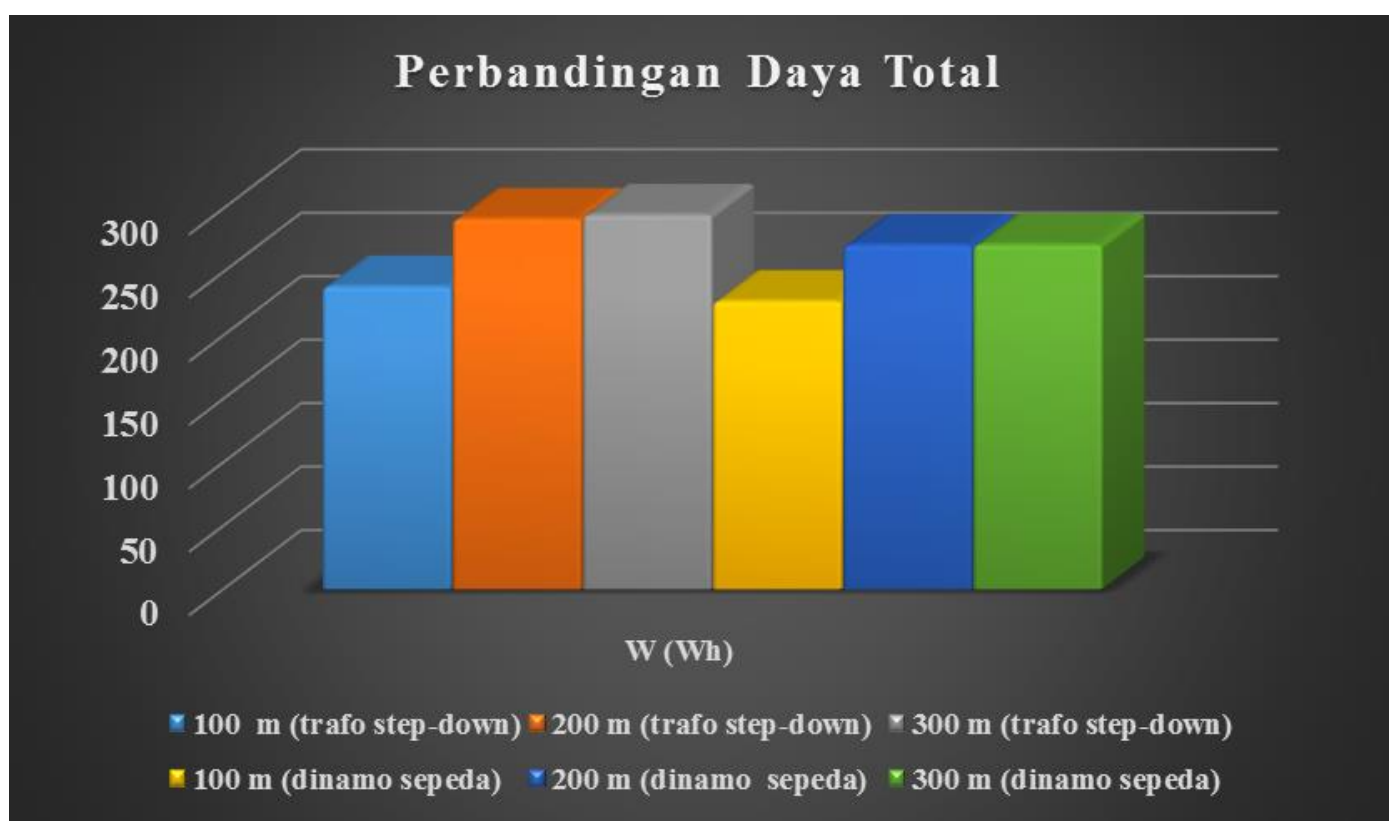

Gambar 4. Perbandingan Daya Total

Hasil perhitungan energi yang terjadi pada baterai didapat bahwa nilai energi yang berasal dari sepeda listrik yang menggunakan dinamo sepeda lebih kecil daripada nilai energi yang berasal dari sepeda listrik yang menggunakan trafo step-down. Berikut akan dijelaskan pada gambar 5 .

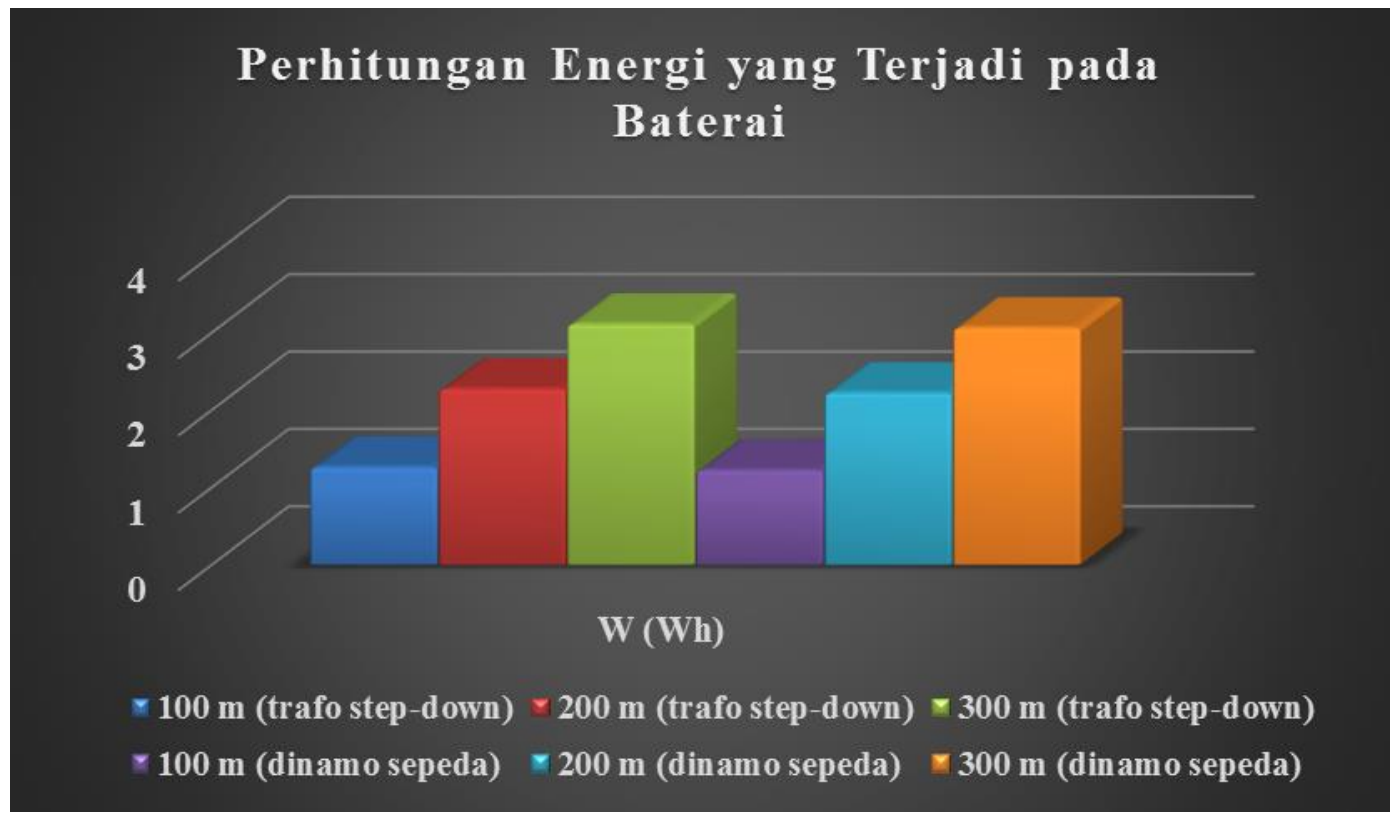

Gambar 5. Perhitungan Energi yang Terjadi pada Baterai

Nilai perbandingan tarif daya listrik membuktikan bahwa dalam skala rupiah, sepeda listrik yang menggunakan trafo step-down memiliki biaya yang sedikit lebih mahal daripada tarif rupiah sepeda listrik yang menggunakan dinamo sepeda. Berikut akan dijelaskan pada gambar 6 . 


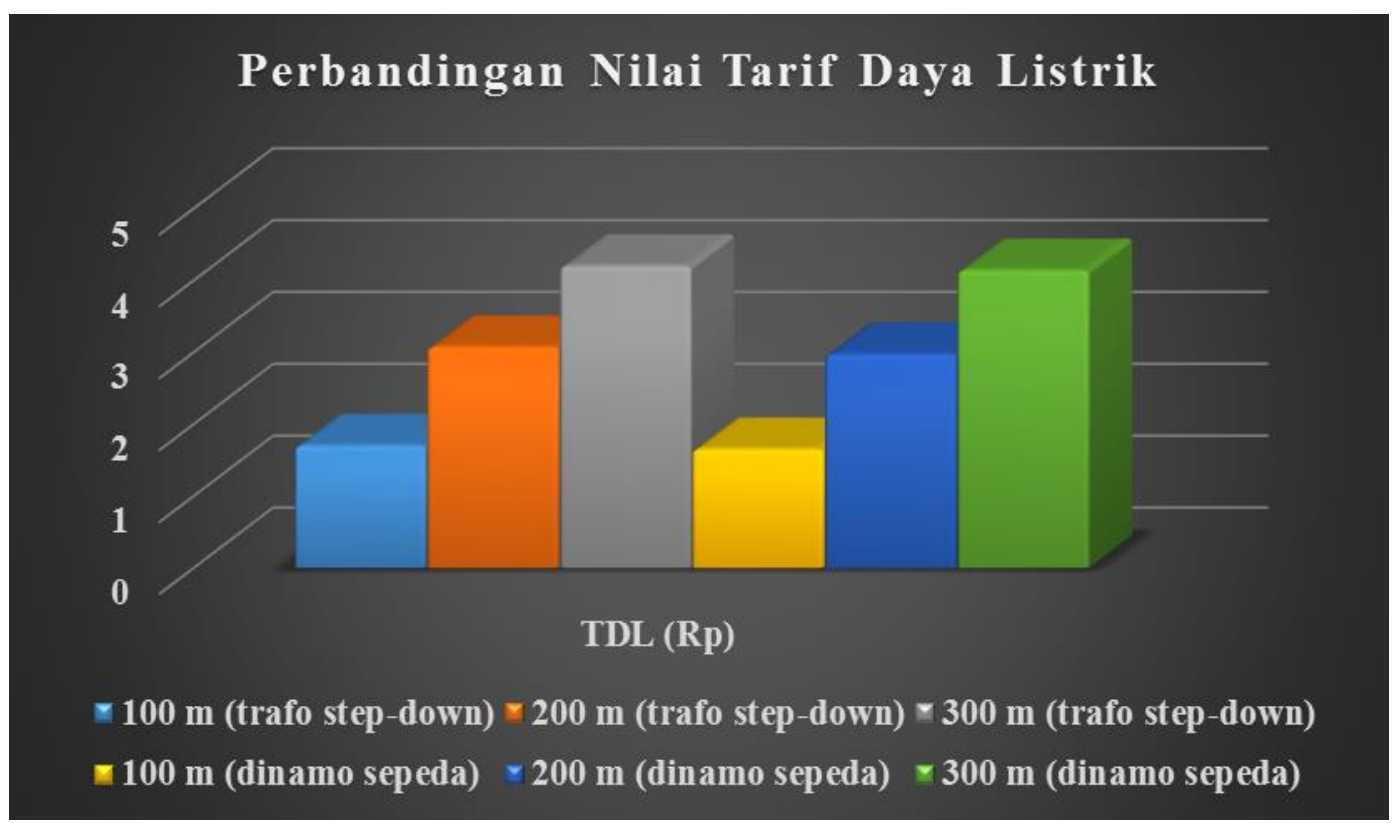

Gambar 6. Perbandingan Nilai Tarif Daya Listrik

Rencana perbaikan sebagai penelitian lebih tepatnya dipasang dua buah dinamo sepeda di tiap roda. Jika dipasang 4 buah berarti 2 buah dinamo di posisi kiri dan kanan dan roda depan dan belakang. Pada penelitian tidak mensimulasikan semua dinamo yang ada agar dapat mengetahui besar perbedaan nilai tarif dasar listrik untuk jarak tertentu.

\section{KESIMPULAN}

Optimasi sebuah penelitian khususnya terkait sepeda motor listrik harus memperhatikan kebaruan penelitian yang akan ditujukan sebagai inti dari penelitian, dari penelitian ini terbukti bahwa sepeda motor listrik dengan dinamo sepeda dapat meningkatkan efisiensi dalam hal konsumsi energi dibanding sepeda motor listrik dengan teknologi trafo step-down sekalipun, bahkan sistem ini jauh lebih baik dari sepeda motor listrik biasa. Optimasi penelitian dengan menambahkan dinamo sepeda sebagai generator dapat menghemat daya hingga $0.05 \mathrm{Wh}$ pada jarak $300 \mathrm{~m}$. Terbukti dalam penelitian di jarak $300 \mathrm{~m}$, E-Bike yang menggunakan dinamo sepeda hanya menghabiskan harga
Rp 4,14/300 m, E-Bike yang menggunakan trafo menghabiskan harga $\mathrm{Rp} \mathrm{4,2/300} \mathrm{m.}$ Daya listrik pada jarak $300 \mathrm{~m}$ dengan dinamo sepeda menghabiskan daya 271.59 W sedangkan daya listrik pada jarak $300 \mathrm{~m}$ dengan trafo step-down menghabiskan daya $295.02 \mathrm{~W}$, dan terbukti dinamo sepeda lebih efisien dalam konsumsi energi listrik.

\section{DAFTAR PUSTAKA}

Alifyanti, D. F. (2016). Pengaturan Tegangan Pembangkit Listrik Tenaga Surya (PLTS). Jurnal Kajian Teknik Elektro, 79-95.

Amir, Yuseva, D. S., \& Sumanto. (2020). Perancangan Sepeda Listrik dengan Panel Surya Tipe J-Feather sebagai Sumber Energi. Malang: Universitas Widyagama Malang.

Abagnale, C., Cardone, M., Iodice, P., Marialto, R., Strano, S., Terzo, M., \& Vorraro, G. (2016). Design and development of an innovative e-Bike. Energy Procedia, 101, 774-781.

Dahlan, D., Zariatin, D. L., \& Wibowo, N. (2018, December). Perancangan Sistem Pemantauan Kecepatan dan 
Praxis : Jurnal Sains, Teknologi, Masyarakat dan Jejaring | Vol. 4 | No. 1 | September 2021

Pengelolaan Baterai pada Sepeda Motor Listrik $3 \mathrm{~kW}$. In Prosiding Seminar Rekayasa Teknologi (SemResTek) (pp. 366-372).

E-Bike, E. E. C. O., \& SIDE, K. C. F. E. (2020). JOJAPS.

Harfit, A. R. (2013). Kajian Mobil Hybrid dan Kebutuhannya di Indonesia. Jakarta: Program Pasca Sarjana Universitas Gunadarma.

Huda, N., \& Khamami, F. (2017). Modifikasi Sistem Kendali Sepeda Listrik Hybrid. Jurnal Cahaya Bagaskara, 1-6.

Hutabalian, R., \& Hamzah, A. (2016). Desain Dan Analisa Inverter Tiga Fasa Dengan Metode SVPWM Sebagai Penggerak Motor Induksi Tiga Fasa Pada Aplikasi Sepeda Listrik (Doctoral dissertation, Riau University).

Ismail. (2020). Perancangan Sepeda Manual menjadi Sepeda Listrik menggunakan Komponen Penggerak Motor Listrik, Baterai dan Kontroler. Makassar: Jurusan Fisika Fakultas Sains dan Teknologi Universitas Islam Negeri Alauddin.

Isnur Haryudo, S. U. B. U. H. (2019). Rancang Bangun Sistem Monitoring Motor Dc Menggunakan Matlab Berbasis Arduino. Jurnal Teknik Elektro, 8.

Priansa, O. A. (2019). Baterai Kendaraan sebagai solusi atas tantangan global mengenai peningkatan kendaraan mobil listrik tahun 2030 di indonesia bagi PT Pertamina Lubricants.

Prasetyo, E., Dahlan, D., \& Fadhli, R. N. (2018, December). Analisis Pengujian Sepeda Motor Listrik $3 \mathrm{~kW}$ Pada Jalan Mendatar dan Menanjak. In Prosiding Seminar Rekayasa Teknologi (SemResTek) (pp. 47-53).

Sepdian, S., \& Subama, E. (2019). Perhitungan Kapasitas Penyimpanan Energi Pembangkit Listrik Tenaga Hibrid Berbasis Energi Surya Dan Energi Angin. Prosiding SENIATI, 144-147.
Surapati, A., \& Priyadi, I. (2017). Rancang Bangun Mobil Hybrid (Tenaga Angin dan Tenaga Surya) Zero Pullution. Prosiding Semnastek.

Puspita, S. C., Sunarno, H., \& Indarto, B. (2017). Generator termoelektrik untuk pengisisan aki. JFA (Jurnal Fisika dan Aplikasinya), 13, 84-87.

Noor, F. A. (2017). Pengaruh Penambahan Kapasitor terhadap Tegangan, Arus, Faktor Daya, dan Daya Aktif pada Beban Listrik di Minimarket. Semarang: Jurusan Teknik Elektro Fakultas Teknik Universitas Negeri Semarang.

Prayoga, S. I. (2017). Desain Sepeda Listrik sebagai Sarana Penunjang Mobilitas Staff Industri PT. INKA. Surabaya: Departemen Desain Produk Fakultas Teknik Sipil dan Perencanaan Institut Teknologi Sepuluh Nopember.

Saodah, S., \& Hariyanto, N. (2019). Perancangan Sistem Pembangkit Listrik Hybrid dengan Kapasitas 3 kVA. Prosiding Seminar Nasional Penelitian dan Pengabdian Pada Masyarakat (pp. 187-190). Pangkalpinang: Proceedings of National.

Simatupang, D. A., Dewadi, F. M., Nugraha, M., \& Muhammad Rafdi. (2013). Sepeda Listrik dengan Sistem Isi Ulang Mandiri. Depok: Jurusan Teknik Mesin Politeknik Negeri Jakarta.

Siregar, A. S., \& Dahlan, D. (2020). Performance Analysis of $48 \mathrm{~V}$ Li-Ion BatteryElectrical Energy Consumption o E-Bike $3 \mathrm{~kW}$ Capacity from Economic Side. JOJAPS, 19-35.

Siswoyo, R., Agustianto, T., P, A. R., H, A. Z., S, R., \& As'adi, M. (2014). Penerapan Teknologi Hybrid pada Kendaraan Sepeda Motor 4 Langkah Berkapasitas 100 cc dengan Menggunakan Alternator. BINA WIDYA, 22-28.

W.H, M. B. (2020). Pengaruh Penggunaan Katalisator Broquet dan Eco Racing terhadap Performa Mesin Sepeda 
Praxis : Jurnal Sains, Teknologi, Masyarakat dan Jejaring | Vol. 4 | No. 1 | September 2021

Motor 4 Langkah 110 cc. Semarang:

Pendidikan Teknik Otomotif Jurusan

Teknik Mesin Fakultas Teknik

Universitas Negeri Semarang.

Wijaya, J. I. (2015). Perancangan dan

Pemilihan Komponen Sistem

Penggerak Sepeda Listrik dengan

Frame Bahan Komposit. Bandung:

Jurusan Teknik Mesin Fakultas Teknik

Universitas Pasundan.

Wildan, P. (2019). Implementasi Alat

Akses Kunci Elektronik Panel Listrik

Berbasis Bluetooth Menggunakan

Smartphone. Medan: Program Studi

Teknik Elektro Fakultas Teknik

Universitas Muhammadiyah Sumatera

Utara. 